\title{
Induction of P3NS1 Myeloma Cell Death and Cell Cycle Arrest by Simvastatin and/or $\boldsymbol{\gamma}$-Radiation
}

\author{
Ibrahim Y Abdelrahman ${ }^{1}$, Reham Helwa ${ }^{2 *}$, Hausein Elkashef ${ }^{1}$, Nagwa H A \\ Hassan $^{2}$
}

\begin{abstract}
The present study was conducted to investigate the effect of $\gamma$-radiation alone or combined with a cytotoxic drug, simvastatin, on viability and cell cycling of a myeloma cell line. P3NS1 myeloma cells were treated with the selected dose of simvastatin $(0.1 \mu \mathrm{M} / \mathrm{l}) 24$ hours prior to $\gamma$-irradiation $(0.25,0.5$ and $1 \mathrm{~Gy})$. The cell viability, induction of apoptosis, cell death, cell cycling, generation of ROS, and expression of P53, Bax, Bcl2, caspase3, PARP1 and Fas genes were estimated. The results indicated that simvastatin $(0.1 \mu \mathrm{M} / \mathrm{l})$ treatment for 24 hours prior to $\gamma$-irradiation increased cell death to $37.5 \%$ as compared to $4.81 \%$ by radiation $(0.5 \mathrm{~Gy})$ alone. It was found that simvastatin treatment before irradiation caused arrest of cells in G0/G1 and G2/M phases as assessed using flow cytometry. Interestingly, simvastatin treatment of P3NS1 cells increased the intracellular ROS production and decreased antioxidant enzyme activity with increased P53, Bax and Caspase3 gene expression while that of Bcl2 was decreased. Consequently, our results indicated that pre-treatment with simvastatin increased radio sensitivity of myeloma tumor cells in addition to apoptotic effects through an intrinsic mitochondrial pathway.
\end{abstract}

Keywords: Simvastatin - $\gamma$-irradiation - cytotoxicity - oxidative stress - antioxidant - apoptosis - myeloma cells

Asian Pac J Cancer Prev, 16 (16), 7103-7110

\section{Introduction}

A major therapeutic approach for the cancer treatment is chemotherapy alone or combined with radiation. Drug resistance (Holohan et al., 2013), recurrence and metastasis (Park et al., 2013) and severe side effects of radio/chemotherapy which lead to death in some cases (Ohe, 2002) are considered the main problems in tumor treatment. Therefore, it is important to develop cancer treatment protocols through increasing cytotoxicity of the tumor cells using radiation alone or in combination with new tumor selective cytotoxic agents in addition to post treatment to prevent recurrence.

Statins are a family of drugs that used to lower cholesterol levels by inhibiting the enzyme 3-hydroxy3-methylglutaryl-coenzyme A (HMG-CoA) reductase, which plays a central role in the production of cholesterol in the liver. Simvastatin has been used widely as an anti-inflammatory drug in many cases; such as Diabetic neuropathy (Chiang and Wang, 2012), improving renal functions (Sandhu et al., 2006), heal coronary heart disease (Pedersen et al., 1998), and some other vascular events (Rao and Milbrandt, 2010). Some publications on statins have been used to investigate its efficacy for killing and/or inhibiting some kinds of tumor; cervical cancer (Crescencio et al., 2009), multiple sclerosis (Awad et al.,
2011), breast cancer (Bjarnadottir et al., 2013), Killing leukemia cell line (Boyunağa, 2013), Lymphoblast and myeloma cells (Cafforio et al., 2005), Lung cancer (Tan et al., 2013), Prostate cancer (Goc et al., 2012), and hepatic cancer (Relja et al., 2010).

Statins are classified into two categories according to its source, natural statins or synthetic statins. The natural statins include Simvastatin, Pravastatin, Mevastatin and Lovastatin. While the synthetic statins include Atorvastatin, Rosuvastatin, Fluvastatin, Pitavastatin, and Cerivastatin (Schachter, 2005).

Ionizing radiation (IR) is the most important tool for cancer treatment where nearly $50 \%$ of all cancer cases receiving radiation therapy showed $40 \%$ curative (Baskar et al., 2012). IR and cytotoxic drugs are used in the treatment of cancer promoting apoptosis in many tumor cell types. It may combined with other types of cancer therapy, such as chemotherapy or immunotherapy and/ or hormonal Therapy (Newton and Strasser, 2000). IR at lethal dose kills cancer cells by two mechanisms, direct and indirect mechanisms. The first mechanism is directly acts on DNA molecule leading to chromosomal breakage either to form a single-strand break (SSB) or doublestrand break (DSB). The second mechanism; indirect, is related to the excessive production of free radicals and increasing oxidative stress leading to apoptosis, in addition 
to decreasing of the antioxidant enzymes activities (Baskar et al., 2012).

In the present study, we used Simvastatin (a natural extract of a fermentation product of Aspergillus terreus) (Xie and Tang, 2007), as well as $\gamma$-irradiation $(\gamma$-IR) at specific doses. The study focused on the role of Simvastatin and/or $\gamma$-radiation on cell viability, cell cycle, Antioxidant enzymes activity, reactive oxygen free radicals, Nitric oxide species, and expression of certain genes (P53, bcl2, Bax, FAS, PARP1 and caspase3).

\section{Materials and Methods}

\section{Cell culture and handling conditions}

Mouse Myeloma cell line, P3NS1 (ATCC) was obtained from NAMRU3, Cairo, Egypt, Tissue Culture Laboratory. Cells were maintained in DMEM with $20 \%$ FBS with $\mathrm{PH} 7.4$ at $37^{\circ} \mathrm{C}$ in a humidified atmosphere of $5 \% \mathrm{CO}_{2}$ and $95 \%$ air.

\section{Simvastatin and radiation treatment}

Simvastatin was obtained from Sharon Bio-Medicine (Navi Mumbai, India) and dissolved in $0.01 \%$ DMSO (Sigma-Aldrich). The present study includes the following groups: 1- Control group without any treatment, 2$\gamma$-irradiated group (Eight subgroups), 3- Simvastatin treated group (Six sub-groups) and 4- Simvastatin and $\gamma$-irradiated group (Three subgroups). In current experiments, the cells were plated with viability more than $85 \%$ and treated with different doses of Simvastatin $(0.05 \mu \mathrm{mol} / 1,0.1 \mu \mathrm{mol} / 1,0.5 \mu \mathrm{mol} / 1,1 \mu \mathrm{mol} / 1,2 \mu \mathrm{mol} / 1$, and $5 \mu \mathrm{mol} / \mathrm{l}$ ), then the cells were harvested at 24hour, 48 hours and 72 hours. For radiotherapy, cells were treated with different doses of $\gamma$-radiation $(0.25 \mathrm{~Gy}$, 0.5Gy, 1Gy, 1.5Gy, 5Gy, 6Gy, 7.5Gy and 10Gy) from $\mathrm{Cs}^{137}$ with dose rate $0.45 \mathrm{~Gy} / \mathrm{min}$ or in combination with Simvastatin. In both experiments; untreated control was our reference. For combination treatments, Simvastatin $(0.1 \mu \mathrm{mol} / \mathrm{l})$ was added to the culture media 24 hours prior to radiation treatment $(0.25 \mathrm{~Gy}, 0.5 \mathrm{~Gy}$, and $1 \mathrm{~Gy})$. The initial experiments which include all different doses of Simvastatin and $\gamma$-IR were performed in three replicate for each dose and then repeated after choosing the selected dose of Simvastatin $(0.1 \mu \mathrm{mol} / \mathrm{l})$ and three doses of $\gamma$-IR (0.25Gy, 0.5Gy, 1Gy).

To estimate the total number of cells $/ \mathrm{ml}$ and its viability percentage, $100 \mu 1$ of cells suspension were mixed with $20 \mu 1$ of vital dye (Trypan blue $0.2 \%$ ) then, $10 \mu 1$ of the suspension were taken for counting with Hemocytometer.

\section{Analysis of cell cycle phases by flow cytometry}

DNA content was analyzed by propidium iodide (PI) staining followed by cytometric analysis using the Cycle TEST $^{\text {TM }}$ PLUS (DNA reagent kit). After treating with simvastatin (48 hours) and/or exposing to $\gamma$-radiation ( 24 hours), cells were harvested at $\left(5 \times 10^{5}\right.$ cells $)$ and were washed with PBS then resuspend in $0.5 \mathrm{ml}$ of PBS. The cells were incubated in $250 \mu 1$ of solution A (Trypsin Buffer) for 10 minutes at room temperature then $200 \mu 1$ of Solution B (Trypsin Inhibitor and RNase buffer) was added and incubated for 10 minutes at room temperature. Then, $200 \mu 1$ of cold $\left(2^{\circ} \mathrm{C}\right.$ to $\left.8^{\circ} \mathrm{C}\right)$ Solution $\mathrm{C}$ (Propidium Iodide staining solution) was added and incubated on ice for 10 minutes in dark. Finally, the samples were filtered through $50-\mu$ m nylon mesh into a labeled $12 \times 75 \mathrm{~mm}$ tube and immediately subjected to flow cytometric analysis with a Becton Dickinson Facscalibur instrument using Modfit program.

Estimation of intracellular reactive oxygen species (ROS), nitric oxygen species (NOS) and antioxidant enzymes activity

The cells were harvested with count $1 \times 10^{6} \mathrm{cells} / \mathrm{ml}$ after washing with PBS and centrifuged at $900 \mathrm{rpm}$ for $5 \mathrm{~min}$ at $4^{\circ} \mathrm{C}$. Cell pellets were homogenized in $0.5 \mathrm{ml}$ of cold PBS and Centrifuged at $14000 \mathrm{rpm}$ for 15 minutes at $4^{\circ} \mathrm{C}$. Then, Supernatants were stored for assay at $-80^{\circ} \mathrm{C}$. After samples preparation; Hydrogen peroxide $\left(\mathrm{H}_{2} \mathrm{O}_{2}\right)$, Nitric oxide (NO), Lipid Peroxidation/Malondialdehyde (MDA), Glutathione peroxidase (GPX), superoxide dismutase (SOD) and Catalase (CAT) were measured according to the manufacturer protocols (Biodiagnostic Co., Egypt).

\section{RNA extraction and $q R T P C R$}

Total cellular RNA was extracted from samples according to the Thermo Scientific RNA Purification Kits (Thermo Scientific co., USA). mRNA was reversely transcribed by First Strand cDNA Synthesis Kit according to manufacturer's instructions (Thermo Scientific co., USA). The qRT-PCR was performed using RNA-direct SYBR Green Real Time PCR master mix (Invitrogen ${ }^{\mathrm{TM}}$ ) on Mx3000P qPCR system (Agilent Technologies, California, USA). The sequences of the forward and reverse primers for mice P53, Bax, BCL-2, PARP1, Caspase- 3 and FAS genes were quoted from previous studies as shown in table (1) (Lim et al., 2004; Mikael and Rozen, 2008; Hamann et al., 2009; Cheng et al., 2010). The CT values were obtained and normalized to GAPDH. Fold changes were calculated using $2^{-\Delta \Delta \mathrm{CT}}$ method.

Table 1. Shows the Forward and Reverse Primer Sequences for Genes were Used in Addition to Housekeeping Gene

\begin{tabular}{lll}
\hline Gene (Mouse) & Forward & Reverse \\
\hline GAPDH & 5-CAGGAGCGAGACCCCACTAACAT-3 & 5-GTCAGATCCACGACGGACACATT-3 \\
Bax & 5'- CCAGGATGCGTCCACCAAGA-3' & 5'- GGTGAGGACTCCAGCCACAA -3' \\
Bcl-2 & 5'- TTC GCAGAG ATG TCC AGTCA -3' & 5'- TTC AGAGAC AGC CAG GAG AA -3' \\
P53 & 5'-GGCAACTATGGCTTCCACCT-3' & 5'-AACTGCACAGGGCACGTCTT- 3 \\
PARP-1 & 5'-GTCCAACAGGAGCATGTGCA-3' & 5' -CCAGCGGTCAATCATACCCA-3' \\
Caspase3 & 5'-CAAGTCAGTGGACTCTGGGA-3' & 5' -CGAGATGACATTCCAGTGCT-3' \\
FAS & 5'-TTCTGTCTACTGAACTTCGGGGTGATCGGTCC-3' & 5'-GTATGAGATAGCAAATCGGCTGACGGTGTGGG-3' \\
\hline
\end{tabular}




\section{Statistical analysis}

All results were analyzed using the Statistical Package for the Social Sciences (SPSS) program, version 14.0. Statistical evaluations of cell viability has been performed on experimental data in a three replicate for each dose and time intervals at 24, 48 and 72 hours and these data were represented as mean \pm SE (standard deviation from the mean) and compared by Two-way analysis of variance (ANOVA) where there were two dependent factors (Time and Dose). For the selected doses groups; data were represented as mean $\pm \mathrm{SE}$ and compared by one-way analysis of variance (ANOVA) with Post-HOC multiple comparisons. A p-value of $<0.05$ was considered significant.

\section{Results}

Cytotoxic effects of $\gamma$-Irradiation and Simvastatin on myeloma cells (P3NS1)

The cytotoxic effects of different doses of $\gamma$-IR and different doses of Simvastatin on P3NS1 cells were selected and tested. After 24,48 and 72 hours of treatment with Simvastatin and 24 hours of $\gamma$-IR the cell viability (v.\%) and total cell count (T.C) were calculated by Trypan blue. Cells in suspension showed morphological changes where many deformed cells appeared in addition to cell count decrease in comparison with control as a result of $\gamma$-IR and/or Simvastatin treatment. T.C/ml was decreased using different doses of $\gamma$-IR $(0.25 \mathrm{~Gy}, 0.5 \mathrm{~Gy}$, $1 \mathrm{~Gy}, 1.5 \mathrm{~Gy}, 5 \mathrm{~Gy}, 6 \mathrm{~Gy}, 7.5 \mathrm{~Gy}$ and $10 \mathrm{~Gy}$ ) where the percent of change of TC reached $6 \%,-21 \%,-31 \%,-41 \%$, $-24 \%,-35 \%,-29 \%$ and $-42 \%$ respectively. The effect of different doses of simvastatin $(0.05,0.1,0.5,1,2$ and $5 \mu \mathrm{mol} / \mathrm{l})$ on cell growth of myeloma cells was time and dose dependent manner where the percent of change in T.C reached $-31 \%,-16 \%,-18 \%,-28 \%,-33 \%$ and $-49 \%$ respectively after $24 \mathrm{~h}$ of inoculation. At $48 \mathrm{~h}$ of inoculation the reduction in percent of change of total count reached $-44 \%,-48 \%,-45 \%,-47 \%,-52 \%$ and $-62 \%$ respectively. At $72 \mathrm{~h}$ the percent of change reached $-43 \%,-64 \%$, $-66 \%,-67 \%,-73 \%$ and $-84 \%$ respectively. These results assure the cytotoxicity of both $\gamma$-IR and Simvastatin. The combination therapy between both $\gamma$-IR $(0.25 \mathrm{~Gy}$, $0.5 \mathrm{~Gy}$ and $1 \mathrm{~Gy})$ and simvastatin $(0.1 \mu \mathrm{mol} / \mathrm{l})$ yielding the
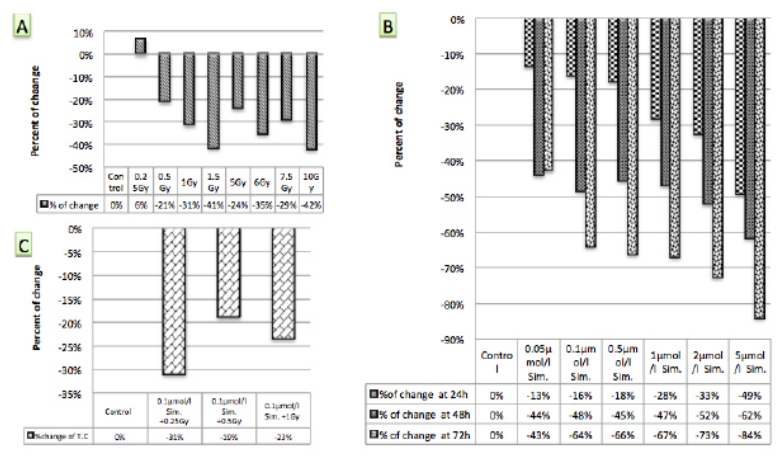

Figure 1.Percent of Change of T.C/ml after Treatment. (A) after $24 \mathrm{~h}$ of $\gamma$-IR exposure with different doses, (B) After inoculation with different doses of simvastatin at 24,48 and 72 hours, (C) After combination therapy between simvastatin and $\gamma$-IR reduction in percent of change of $\mathrm{TC} / \mathrm{ml}$ where it reached $-31 \%,-19 \%$ and $-23 \%$ respectively (Figure 1 ).

Viability percentages decreased with increasing the $\gamma$-IR dose (0.25Gy, 0.5Gy, 1Gy, 1.5Gy, 5Gy, 6Gy, 7.5Gy and $10 \mathrm{~Gy}$ ) it reached $79 \%, 55 \%, 41 \%, 31 \%, 37 \%, 28 \%$, $27 \%$ and $22 \%$ respectively.

Simvastatin doses $(0.05,0.1,0.5,1,2$ and $5 \mu \mathrm{mol} / \mathrm{l})$ induced statistically significant decrease in percentage of viable cells over than the control. Such percentage was dose dependent, as it decreased with increasing the dose, it reached $65 \%, 60 \%, 56 \%, 38 \%, 22 \%$ and $8.9 \%$ as compared with $88 \%$ for the control at 24 hours of treatment and reached 58\%, 49\%, 23\%,22\%, $15 \%$ and $1.83 \%$ compared with $89 \%$ for the control at 48 hours of treatment, while 72 hours after treatment it reached $20 \%$, $0 \%, 0 \%, 0 \%, 4 \%$ and $0 \%$ as compared with control (84\%). At the end of this experiment, the doses which caused cell viability around $50 \%$ were selected. So, $0.1 \mu \mathrm{mol} / 1$ Simvastatin for 48 hours in addition to $0.25,0.5 \mathrm{~Gy}$ and $1 \mathrm{~Gy}$ of $\gamma$-radiation were selected for testing their combined effects. As shown in figure 2, no significant difference between Simvastatin and its combination with $0.25 \mathrm{~Gy}$ (p value $=0.133$ ), but there was a highly significant difference with its combination with $0.5 \mathrm{~Gy}$ ( $\mathrm{p}$ value $\leq 0.01$ ) and $1 \mathrm{~Gy}$ ( $\mathrm{p}$ value $\leq 0.01$ ). It is very important to mentation that, there was no significant difference between the two combination therapy groups of $\gamma$-radiation (0.5Gy \& $1 \mathrm{~Gy}$ ) with simvastatin ( $\mathrm{p}$ value $\leq 0.072$ ). The Simvastatin was added to cell line 24 hours before irradiation. The cells were exposed to $\gamma$-radiation then harvested after 48 hour of simvastatin treatment. The combination effect revealed more additional decrease in cell growth and viability which indicates increasing of radiosensitivity of myeloma cells to $\gamma$-IR.

The effect of simvastatin alone or combined with $\gamma$-IR on
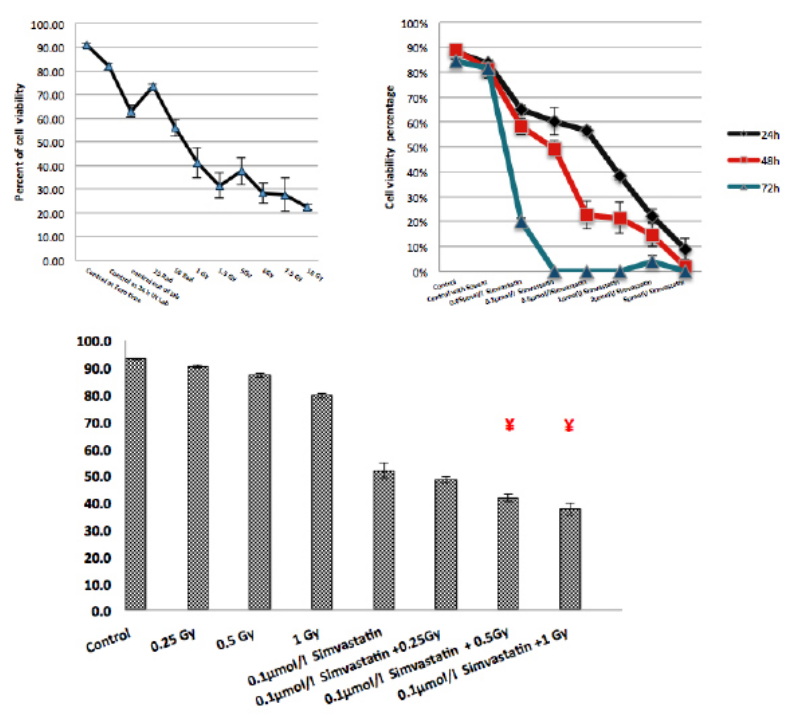

Figure 2. Percentages of Cell Viability of Myeloma Cells. (A) at 24 hours post irradiation with different doses of $\gamma$-rays, (B) cell viability at 24,48 and $72 \mathrm{~h}$ post treatment with different doses of simvastatin, (C) Effect of the selected doses of Gamma irradiation $(0.25 \mathrm{~Gy}, 0.5 \mathrm{~Gy} \& 1 \mathrm{~Gy})$ and a dose of Simvastatin $(0.1 \mu \mathrm{mol} / 1)$ alone or combined on viability percentages of myeloma cells 
Ibrahim Y Abdelrahman et al

Table 2. Shows the Percentage of Cells in Each Phase of the Cell Cycle Obtained with the Modift Software (Becton Dickinson) Showing the Effect of Gamma Irradiation Exposure(0.25Gy, 0.5Gy and 1Gy), Simvastatin $(0.1 \mu \mathrm{mol} / \mathrm{l} \mathrm{Simvastatin)}$ or in Combination with Gamma Irradiation (0.5Gy and 1Gy) on the Phases of the Cell Cycle and cell death. The Cell Cycle was Evaluated by Flowcytometry after 24hours of Gamma Irradiation Treatment but in Case of Simvastatin Treatment or Combination Therapy between Simvastatin and Gamma Irradiation the Cells are Harvested after 48 hours

\begin{tabular}{|c|c|c|c|c|}
\hline \multirow[t]{2}{*}{ Groups } & \multirow[t]{2}{*}{ Cell Death $(\%)$} & \multicolumn{3}{|c|}{ Analysis of cell cycle Phases (\%) } \\
\hline & & G0/G1 & S Phase & $\mathrm{G} 2 / \mathrm{M}$ \\
\hline Control & $1-4$ & 32.04 & 47.39 & 20.58 \\
\hline $0.25 \mathrm{~Gy}$ & 4-78 & $1-25$ & 48.97 & 25.83 \\
\hline $0.5 \mathrm{~Gy}$ & 4-81 & 23.64 & 44.71 & 31.65 \\
\hline $1 \mathrm{~Gy}$ & 4-61 & 26.83 & 50.25 & 22.92 \\
\hline $0.1 \mu \mathrm{mol} / 1 \mathrm{Simvastatin}$ & 42.98 & 34.17 & 30.02 & 35.81 \\
\hline $0.1 \mu \mathrm{mol} / 1$ Simvastatin $+0.5 \mathrm{~Gy}$ & 37.5 & $7-27$ & 23.72 & 48.5 \\
\hline $0.1 \mu \mathrm{mol} / 1$ Simvastatin + 1Gy & 37.82 & 33.77 & 31.9 & 34.33 \\
\hline
\end{tabular}
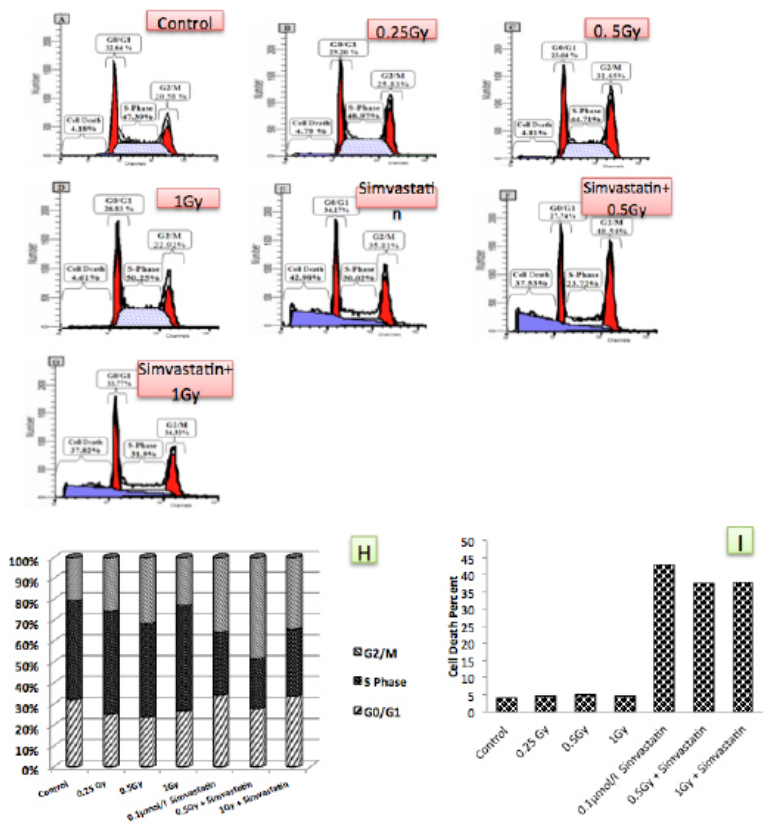

Figure 3. Flow Cytometry Analysis Showing Cell Percentages in Different Phases of Cell Cycle. (A-G) after treatment with simvastatin and radiation alone or combined, (H): The effect of simvastatin and/or Gamma irradiation on arresting cell cycle phases, (I): showing the death rate detected by flow cyctometry under effect of gamma irradiation and/or simvastatin treatment

\section{cell death and cell cycle phases}

The effect of Simvastatin alone or combined with radiation on cell death and cell cycle of P3NS1 myeloma cells were estimated. The cells were assessed by propidium iodide (PI) using flow cytometer after 24 hours of $\gamma$-IR $(0.25 \mathrm{~Gy}, 0.5 \mathrm{~Gy}$ and $1 \mathrm{~Gy})$ and 48 hours of simvastatin $(0.1 \mu \mathrm{mol} / \mathrm{l})$ treatment alone or in combination with either $0.5 \mathrm{~Gy}$ or $1 \mathrm{~Gy}$ of $\gamma$-IR. Twenty thousand cells were passed through the device column and were accumulated in gates according to their cell cycle phase and death as shown in table (2).

Flow cytometric analysis revealed that the myeloma cells exposed to $0.25 \mathrm{~Gy}$ after 24 hours of treatment showed an increase in the number of cells at G2-M Phase ( $25.83 \%$ vs. $20.58 \%$ in the control group). Simultaneously, the number of cells in G0-G1 phase decreased from 32.04
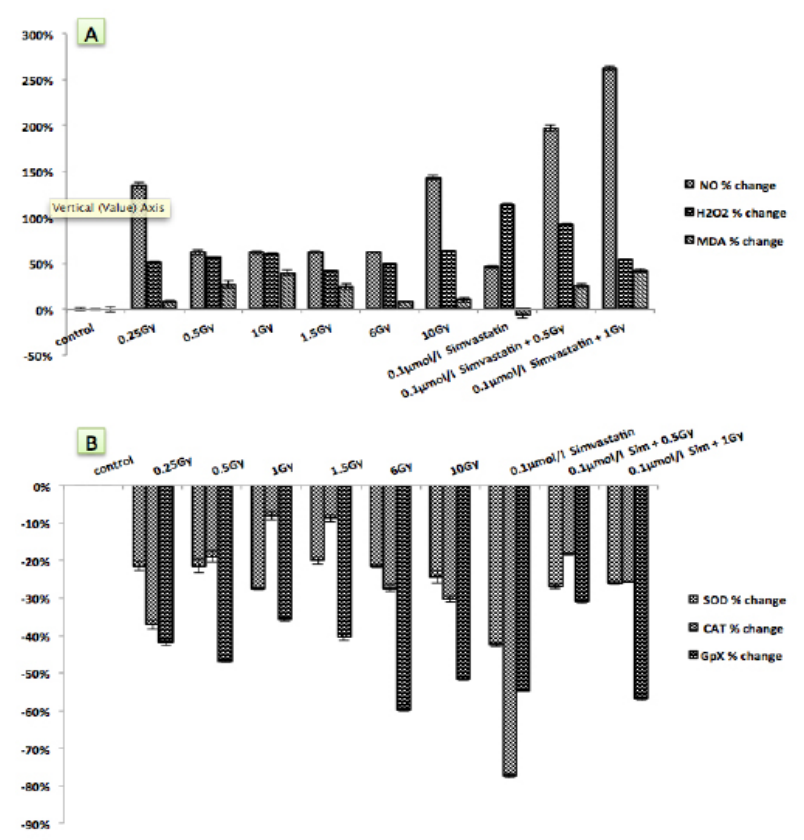

Figure 4. Showing the Change in Oxidative Stress of Myeloma Cells. (A): Percent change of $\mathrm{NO}, \mathrm{H}_{2} \mathrm{O}_{2}$ and MDA in different groups under study, (B): Percent change of SOD, GPX and Cat in different groups under study

$\%$ in the control group to $25.20 \%$ in treated group with $0.25 \mathrm{~Gy}$. On the other hand, group irradiated with $0.5 \mathrm{~Gy}$, showed an increase in the number of cells at G2-M Phase (31.65\% as compared to control group; $20.58 \%$ ). Simultaneously, the number of cells in G0-G1 phase and in S-Phase was decreased from $32.04 \%$ to $23.64 \%$ and from $47.39 \%$ to $44.71 \%$, respectively. In case of using radiation dose $(1 \mathrm{~Gy})$, there was an increase in the number of cells at S-Phase and G2-M Phase $(50.25 \%$ and $22.92 \%$ in the treated cells Compared to $47.39 \%$ and $20.54 \%$ in the control group, respectively), While the number of cells in G0-G1phase were reduced from $32.04 \%$ to $26.83 \%$ as shown in figure 3 .

Simvastatin treatment induced an increase in cells number at G1 and G2-M phases after 48 hours $(34.17 \%$ and $35.81 \%$ vs. $32.04 \%$ and $20.58 \%$ in the control group, respectively). In addition, the S-phase population was decreased from $47.39 \%$ to $30.02 \%$. That is a point of 
interest which this dose of simvastatin induced cell death reached $42.98 \%$ of total cell population.

The combined treatment of simvastatin $(0.1 \mu \mathrm{mol} / \mathrm{l})$ with $\gamma$-IR $(0.5 \mathrm{~Gy})$ showed an increase in the number of cells at G2-M phase (48.54\% vs. $20.58 \%$ in control) and a reduction in the number of cells in G0-G1 and S- phases from $32.02 \%$ and $47.39 \%$ in the control group to $27.74 \%$ and $23.72 \%$, respectively. The combination treatment induced cell death with ratio $37.53 \%$.

High dose of radiation ( $1 \mathrm{~Gy}$ ) combined with simvastatin $(0.1 \mu \mathrm{mol} / \mathrm{l})$ induced an elevation in the number of cells at G0-G1 and G2-M phases (33.77 and $34.33 \%$ vs. $32.02 \%$ and $20.58 \%$ in the control group respectively) while, the number of cells in S- phase was decreased from $47.39 \%$ in the control group to $31.9 \%$. In addition, the combination treatment induced cell death with ratio $37.82 \%$. Twenty thousand cells were passed through the device column and were accumulated in gates according to their cell cycle phase and death as shown in figure 3 .

\section{Changes in ROS and NOS after simvastatin and radiation} treatment alone or combined

$\mathrm{H}_{2} \mathrm{O}_{2}$ production, $\mathrm{NO}$ (Nitrite) and Lipid peroxidation (MDA) were assessed as indicators of oxidative stress of the cells. Radiation treatment resulted in an increase in $\mathrm{H}_{2} \mathrm{O}_{2}$,

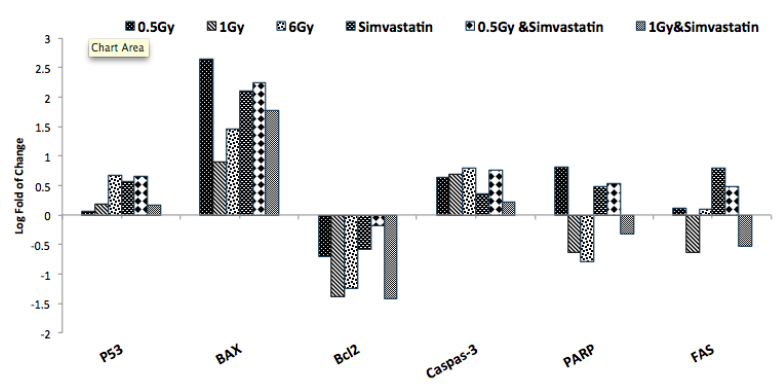

Figure 5. Showing Expression of P53, Bax, Bcl2, Caspase-3, PARP1 and FAS Genes Under the Effect of Gamma Radiation and/or $0.1 \mu \mathrm{mol} / \mathrm{l} \mathrm{Simvastatin}$

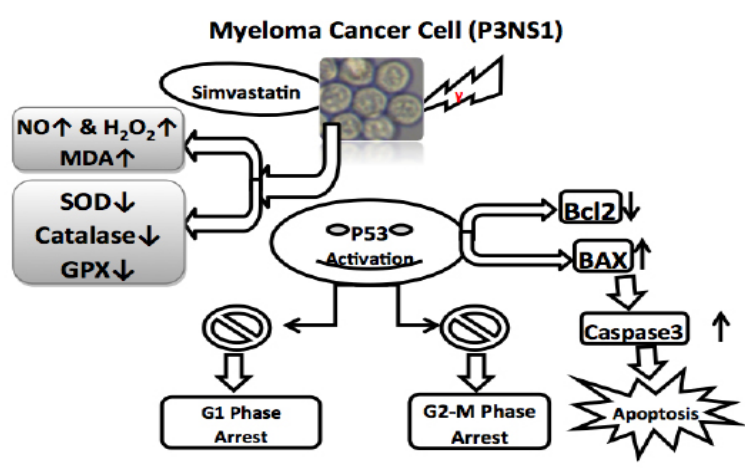

Figure 6. Simvastatin and Gamma Radiation Treatment on Myeloma Cells through Increasing Oxidative Stress Including Nitric oxide, Hydrogen Peroxide, Lipid peroxidation. Intrinsic apoptotic pathway through P53 up-regulation and consequently increasing the Pro-apoptotic Bax and caspase 3 gene expression in addition to down-regulation of Anti-Apoptotic Bcl2 gene expression. The Activation of P53 increases the cytostatic effect through arresting cell cycle at G1Phase and G2M phase
$\mathrm{NO}$ and MDA while simvastatin increased $\mathrm{H}_{2} \mathrm{O}_{2}$ and $\mathrm{NO}$ only, but it had no effect on MDA. Combination treatment of radiation and simvastatin increased significantly $\mathrm{NO}$ as compared to single treatments. Enzymatic activities of CAT, SOD and GPX were assessed. Radiation and simvastatin treatment alone or combined; decreased the activity of these enzymes in comparison to untreated control group as shown in figure 4.

At the molecular level, gene expression of P53, BAX, Bcl2, Caspase3, FAS and PARP1 were assessed in comparison with GAPDH as housekeeping gene. Figure 5 shows all genes under investigation showed up-regulation except the $\mathrm{Bcl} 2$ gene which was down-regulated. These results suggest that the simvastatin can induce apoptosis via mitochondrial dependent pathway.

\section{Discussion}

The development of drug resistance is generally considered the main reason of cancer treatment failure by using radio/chemotherapy. Therefore, the used drugs were often given in combination; in order to reduce incidence of developing resistance. Increased cytotoxicity of tumor cells by radiation in combination with cytotoxic agents was our goal in the present study to increase radio sensitivity of tumor cells.

IR is one of the most important cancer therapy regimens worldwide; it acts directly on vital molecules including DNA which lead to cell death, while indirect effect is represented by the action of free radicals on the biological molecules (Baskar et al., 2012).

Statins have been previously reported to have anticancer properties including different biological parameters such as induction of apoptosis, inhibition of cell growth, arresting cell cycle, decreasing antioxidant enzymes level in tumor tissue, as well as increasing ROS and NOS, regulating apoptotic and anti-apoptotic gene expression (Spampanato et al., 2012; Qiu et al., 2014).

In the present study, the anti-tumor effects of simvastatin and/or $\gamma$-IR on myeloma cells in vitro were investigated. Variable doses of $\gamma$-IR were used for treatment of myeloma cells and the selected doses were determined. Exposure of myeloma cells to different doses of $\gamma$-IR $(0.25,0.5 \mathrm{~Gy}, 1 \mathrm{~Gy}, 1.5 \mathrm{~Gy}, 5 \mathrm{~Gy}, 6 \mathrm{~Gy}, 7.5 \mathrm{~Gy}$ and 10Gy) decreased the cell growth in the dose dependent manner. The percent of change of myeloma cells total count per $\mathrm{ml}$ reached $6 \%,-21 \%,-31 \%,-41 \%,-24 \%$, $-35 \%,-29 \%$ and $-42 \%$ respectively after 24 hours of $\gamma$-IR as shown in figure (1A). The T.C/ml decreased due to the effect of $\gamma$-IR except in the dose of $0.25 \mathrm{~Gy}$ we noted that the growth cells were activated in comparison to control which assuring the basics of Hormesis theory of radiation (Robinson, 2013). Those results agreed with those reported by Algur, Macklis et al. 2005 (Algur et al., 2005) where they found that the radiation enhanced in vitro cytotoxicity for both human prostate and myeloma cancer cell lines.

The applied simvastatin doses $(0.05,0.1,0.5,1,2$ and $5 \mu \mathrm{mol} / \mathrm{l}$ ) induced statistically significant decrease in the cell growth in dose and time dependent manner. The percent of change in cell growth reached $-49 \%$ of 
total count of myeloma cells using the highest dose of simvastatin at 24 hours. After 48 hours of treatment, the percent of change reached $-62 \%$. Seventy two hours post treatment the reduction of cell growth reached $-84 \%$ (figure 1B). Also, Reljia, Meder et al. 2010 (Relja et al., 2010) reported that simvastatin effectively suppressed tumor cell growth of HepG2 and Huh7 cells. In several human malignancies, including breast, colon, prostate cancer and melanoma, simvastatin had selective anticancer effects due to the cell cycle arrest in the G1 and G2/M phases, therefore inhibiting the cell proliferation as well as apoptotic and necrotic cell death induction (Saito et al., 2008).

The data regarding cell viability $24 \mathrm{~h}$ after exposure to different doses of $\gamma$-IR showed decrease in the percentage of viable cells in a dose dependent manner compared to control. Radiation doses exhibit remarkable effect on inhibiting viability at the initial time of cell passaging for example in a dose of $1 \mathrm{~Gy}$ the viability percentage was $41.22 \%$ versus $90.98 \%$ in control group. After a while; the tumor cells became more resistant and the percentage reached $79.6 \%$ vs. $93 \%$, this could attributed to increase in cell resistance. This results support the work of (Gregoire et al., 2001) who reported that cell resistance increased with increasing cell passaging numbers.

The applied simvastatin doses induced statistically significant decrease in the percentage of viable cells. This effect was time and dose dependent, since a simvastatin pre-treatment for $72 \mathrm{~h}$ significantly reduced the number of viable cells to reach $0 \%$ as compared to 48 and $24 \mathrm{~h}$ postinoculation. These results strongly suggested the cytotoxic effect of simvastatin as found by (Kochuparambil et al., 2011) who stated that the Simvastatin inhibits prostate cancer cell proliferation.

Combination between selected doses of $\gamma$-IR $(0.25 \mathrm{~Gy}$, $0.5 \mathrm{~Gy}$ and $1 \mathrm{~Gy})$ and simvastatin $(0.15 \mu \mathrm{mol} / \mathrm{l})$ showed no significant difference with the $0.25 \mathrm{~Gy}$ dose ( $\mathrm{p}$ value $=$ 0.133 ) but it had a highly significant difference with 0.5 and $1 \mathrm{~Gy}$ doses ( $\mathrm{p}$ value $<0.01$ ). These results revealed that simvastatin treated cells exhibited enhanced potentiation of radiation induced inhibition of viability as assessed by trypan blue assay. Reduced survival in response to combined treatments can be owed to increase apoptosis. To elucidate the mechanism of Radiation and simvastatin induced cell growth inhibition and viability reduction, we examined the effect of both Radiation and simvastatin on cell cycle distribution by flow cytometry.

Cell death and cell cycle arrest were confirmed with the results of cell cycle analysis, where the $\gamma$-IR doses $(0.25,0.5$ and $1 \mathrm{~Gy})$ induced cell death reached to $4.79 \%$, $4.81 \%$ and $4.61 \%$ in comparison with $4.18 \%$ for control group. This confirms the results of viability test with Trypan blue indicating to the cell resistance in spontaneous cell passaging. Simvastatin induced cell death reached $42.98 \%$ of total cells and cell cycle arrest at G0/G1 and G2/M phases while the combination therapy induced cell death with ratio $37.5 \%$ in case of combination with $0.5 \mathrm{~Gy}$ and $37.8 \%$ in case of combination with $1 \mathrm{~Gy}$. There is no significant difference between the two mentioned combination groups ( $\mathrm{P}$ values $=0.072)$ which reveals that the simvastatin promote the radio sensitivity of tumor cells which helps in improving the radiotherapy regimens. It should be mention that the same results of cell death were obtained in case of $0.5 \mathrm{~Gy}$ and its double dose (1Gy).

The present data showed that the combination between simvastatin and $\gamma$-IR increased cytostatic cell death by arresting cells at G0/G1 and G2-M phases. The arresting at $\mathrm{G} 2 / \mathrm{M}$ is very important because it is our target for tumor cell therapy as the tumor cell loses its check point at G1 Phase. The check point at G1 phase is a station to interpret different signals for cell division and cell fate, where the cancer cells have uncontrolled cell proliferation (Chen et al., 2012). The cytostatic effect of myeloma cells could be expected by two mechanisms; the first is through controlling gene expression which will be discussed later while, the second expected mechanism is blocking mevalonate pathway which leads to decrease all requirements for vital cell functions (cell proliferation, differentiation and migration) as cholesterol, Isoprenoid metabolites (serve as lipid attachments for number of intracellular signaling molecules) and prenylated proteins (Rac, Ras and Rho) (Thurnher et al., 2012). The arresting at G2/M was agreed with the finding of Zhang, Wu et al. 2010 (Zhang et al., 2010). Arresting of cells treated with statins at G0/G1 phase is supported by findings of Reljia, Meder et al. 2010 (Relja et al., 2010) who reported that simvastatin induced apoptosis and impaired cell cycle progression as depicted by greater rates of G0/G1- phase cells than the rates of S-phase cells. Relja et al 2010 explained simvastatin's cell cycle: suppressive action due to reduce expression of cyclin- dependent kinases (CDKs) and Cyclins, where CDK inhibitors P19 and P27 were enhanced (Crescencio et al., 2009) stated that statin have no effect on cell cycle but have antitumor effect while Tu, Kang et al. 2011 (Tu et al., 2011) found that the arresting take place at S-Phase and having anti-apoptotic effect on myeloma cells as shown in figure (6).

In Case of $\gamma$-IR, the mechanism of cell death has been occurred through an indirect mechanism of radiation effect via increasing oxidative stress (Girdhani et al., 2009), arresting cell cycle at G2/M phase where Cancer cells are typically highly sensitive to radiation killing late in the G2 phase of the cell cycle (Vucic et al., 2006). Deweese Shipman et al. 1998 (Deweese et al., 1998) agreed with our results where they found that the low dose rate radiation exposure of LNCaP cells resulted in an accumulation of cells at both the G1/S and the G2/M cell cycle transition points, but in case of DU 145, PC-3, PPC-1, and TSUPr1 cells, treatment with low dose rate radiation triggered G2/M cell cycle arrest, but not G1/S arrest.

Treatment of cells with simvastatin alone or combined with radiation result in generation of oxidative stress represented by an increase in $\mathrm{H}_{2} \mathrm{O}_{2}$ and MDA, in addition to NO production. This increase in oxidative stress followed by decrease in activities of the antioxidant enzymes SOD, GPX and CAT. Gamma radiation increased the successive production of free radicals which known with the indirect mechanism of radiation to inhibit cell proliferation and induced apoptosis. Simvastatin alone increased the level of $\mathrm{H}_{2} \mathrm{O}_{2}$ and $\mathrm{NO}$ but it has insignificant effect on the level of MDA. This indicated that the simvastatin has less effect on the cell membrane 
breakdown comparable with $\gamma$-IR. Simvastatin and/or $\gamma$-IR significantly increased the production of ROS in the tumor cells in vitro. During tumor cell proliferation; the apoptosis resistance is developed through appearance of membrane-associated catalase, moreover, reducing the catalase activity leads to decreasing the protection value of the tumor cell resulting to the cell death (Bauer, 2011).

The present results showed that simvastatin inhibit cell growth and induced cell apoptosis as previously reported by Wang, Xu et el. 2013 and Qiu, Xie et al. 2014 (Wang et al., 2013; Qiu et al., 2014). It significantly increased $\mathrm{H}_{2} \mathrm{O}_{2}$ capacity which leads to accumulation of ROS. Several studies reported that ROS are key signaling molecules in mammalian cells, its increase is directly related to mitochondrial dysfunction that induced apoptosis (D'Autréaux and Toledano, 2007) . Cell death caused by IR is markedly affected by oxygen levels, where irradiation under hypoxic conditions reduces cell kill. Simvastatin increase response to IR because it increase Oxygen level which leading to cell death (Begg et al., 2011).

Our results indicated that the treatment of tumor cells with $0.1 \mu \mathrm{mol} / 1$ simvastatin and $\gamma$-IR alone or combined caused up regulation of P53 gene expression as represented by (Zhao et al., 2000) who stated that the p53 gene was induced by UV and $\gamma$-irradiation in colon carcimona cell line EB-1. The p53 protein is kept at low levels via its short half-life, but in response to cellular stress the half-life of p53 increases, p53 protein levels rise, and the protein is activated for transcription probably via phosphorylation, acetylation, or other modifications. As a results of this up regulation the expression of Proapoptotic BAX, Caspase3, PARP1, and FAS genes were promoted their function while the anti-apoptotic $\mathrm{Bcl} 2$ gene was down regulated leading to intrinsic apoptosis through mitochondrial pathway. As a result of gene expression cell cycle was arrested at G0/G1 through inhibition of the Cyclin-dependent kinase 2 (CDK2) by phosphorylation (Wang et al., 2013) but in case of its inhibition the phosphorylation of Cyclin-dependent kinase 1 (CDK1 or CDC2) leading to arresting at G2/M (Chow et al., 2003). These results could help in interpretation of a strong apoptosis induction through promoting the gene expression (Zhou et al., 2005). The apoptotic cell death was significantly increased using simvastatin treatment alone and in combination with $\gamma$-IR more than single treatment with $\gamma$-IR through intrinsic and extrinsic pathways which happened through breakdown the phospholipids of cell membrane (Jourdan et al., 2009). IR induced DNA Damage response (DDR), which either halts the cell cycle, preventing transfer of DNA damage to progeny, or facilitates DNA damage repair machinery. Also, it has a crucial role in induction of apoptosis when repair fails (Begg et al., 2011).

Therefore, the doses used for radiotherapy can be minimized up to $50 \%$ by using simvastatin before starting radiotherapy sessions. This will help in decreasing radiation hazards which in turn will leads to minimizing the side effect of radiation which added extra burden load on patient's physiological and psychological activities.

Regarding to the safety of simvastatin, it should be mentioned that statins are considered as safety drugs as a result of (Spampanato et al., 2012) experiments. They have found that the simvastatin has no apoptotic effect on non-cancerous fibroblasts after 3 days of treatment. Although the history of statins on human medication indicated to a myopathy side effect in patients who taken statins for long term, but this side effect represents a low risk in comparison with cancer complains, radiotherapy and chemotherapy side effects (Bhardwaj et al., 2013).

In conclusion, this study indicates that simvastatin alone is able to induce apoptosis in P3NS1 myeloma cell line or in combination with $\gamma$-IR. Furthermore; simvastatin increased radio sensitivity which may lead to decreasing the radiation dosage in radiotherapy regimens. So, the side effect of radiation can be decreased in cancer patients. The mechanism of apoptosis induction seems to depend on regulation of $\mathrm{P} 53, \mathrm{Bax}, \mathrm{Bcl} 2$ and caspase- 3 genes expression through intrinsic apoptotic pathway.

The importance of this study will be highly significant if we estimated the measured parameters after treatment with more drugs in order to increase the cancer cell death and evaluate the synergism with simvastatin. To assure these effects, further studies on animal models are needed to verify simvastatin effect in addition to its effect with other anticancer drug combination. Moreover, this study prospect sophisticated studies in order to use specific genes as prognostic and diagnostic marker in radiation hazards and treatment.

\section{References}

Algur E, Macklis RM, Häfeli UO (2005). Synergistic cytotoxic effects of zoledronic acid and radiation in human prostate cancer and myeloma cell lines. International Journal of Radiation Oncology* Biology* Physics, 61, 535-42.

Awad AM, Sellner J, Hemmer B, et al (2011). Role of statins in the treatment of multiple sclerosis: an update. Neurodegenerative Disease Management, 1, 109-14.

Baskar R, Lee KA, Yeo R, et al (2012). Cancer and radiation therapy: current advances and future directions. International J Med Sci, 9, 193.

Bauer G (2011). Low dose gamma irradiation enhances defined signaling components of intercellular reactive oxygen-mediated apoptosis induction. Journal of Physics: Conference Series. IOP Publishing, 012001.

Begg AC, Stewart FA, Vens C (2011). Strategies to improve radiotherapy with targeted drugs. Nature Reviews Cancer, 11, 239-53.

Bhardwaj S, Selvarajah S, Schneider EB (2013). Muscular effects of statins in the elderly female: a review. Clinical Interventions in Aging, 8, 47.

Bjarnadottir O, Romero Q, Bendahl P-O, et al (2013). Targeting HMG-CoA reductase with statins in a windowof-opportunity breast cancer trial. Breast Cancer Research and Treatment, 138, 499-508.

Boyunağa H (2013). The Effects of Ara-C, Simvastatin and combo therapy on energy metabolism of HL-60 promyolocytic leukemia cell lines. Türk Biyokimya Dergisi [Turkish Journal of Biochemistry-Turk J Biochem], 38, 31-6.

Cafforio P, Dammacco F, Gernone A, et al (2005). Statins activate the mitochondrial pathway of apoptosis in human lymphoblasts and myeloma cells. Carcinogenesis, 26, 883-91.

Chen T, Stephens PA, Middleton FK, et al (2012). Targeting the 
Ibrahim Y Abdelrahman et al

$\mathrm{S}$ and G2 checkpoint to treat cancer. Drug discovery today, 17, 194-202.

Cheng G-H, Wu N, Jiang D-F, et al (2010). Increased Levels of p53 and PARP-1 in EL-4 cells probably related with the immune adaptive response induced by low dose ionizing radiation in vitro. Biomedical and Environmental Sciences, 23, 487-95.

Chiang C-E, Wang K-L (2012). Statin, Risk of diabetes and impacts on mortality: insight from taiwan national health insurance database. J Am College Cardiol, 59, 1657.

Chow JP, Siu WY, Ho HT, et al (2003). Differential contribution of inhibitory phosphorylation of CDC2 and CDK2 for unperturbed cell cycle control and DNA integrity checkpoints. J Biological Chemistry, 278, 40815-28.

Crescencio ME, Rodríguez E, Páez A, et al (2009). Statins inhibit the proliferation and induce cell death of human papilloma virus positive and negative cervical cancer cells. International journal of biomedical science: IJBS, $\mathbf{5}, 411$.

D’Autréaux B, Toledano MB (2007). ROS as signalling molecules: mechanisms that generate specificity in ROS homeostasis. Nature reviews Molecular Cell Biol, 8, 813-24.

Deweese TL, Shipman JM, Dillehay LE, et al (1998). Sensitivity of human prostatic carcinoma cell lines to low dose rate radiation exposure. J Urol, 159, 591-8.

Girdhani S, Ahmed MM, Mishra KP (2009). Enhancement of gamma radiation-induced cytotoxicity of breast cancer cells by curcumin. Molecular and Cellular Pharmacology, 1, 208-17.

Goc A, Kochuparambil ST, Al-Husein B, et al (2012). Simultaneous modulation of the intrinsic and extrinsic pathways by simvastatin in mediating prostate cancer cell apoptosis. BMC Cancer, 12, 409.

Gregoire L, Rabah R, Schmelz E-M, et al (2001). Spontaneous malignant transformation of human ovarian surface epithelial cells in vitro. Clinical Cancer Research, 7, 4280-7.

Hamann S, Schorderet DF, Cottet S (2009). Bax-induced apoptosis in Leber's congenital amaurosis: a dual role in rod and cone degeneration. PloS One, 4, 6616.

Holohan C, Van Schaeybroeck S, Longley DB, et al (2013). Cancer drug resistance: an evolving paradigm. Nature Reviews Cancer, 13, 714-26.

Jourdan M, Reme T, Goldschmidt H, et al (2009). Gene expression of anti and pro apoptotic proteins in malignant and normal plasma cells. Br J Haematol, 145, 45-58.

Kochuparambil ST, Al-Husein B, Goc A, et al (2011). Anticancer efficacy of simvastatin on prostate cancer cells and tumor xenografts is associated with inhibition of Akt and reduced prostate-specific antigen expression. $J$ Pharmacol Experimental Therapeutics, 336, 496-505.

Lim KM, Yeo WS, Chow VT (2004). Antisense abrogation of DENN expression induces apoptosis of leukemia cells in vitro, causes tumor regression in vivo and alters the transcription of genes involved in apoptosis and the cell cycle. International J Cancer, 109, 24-37.

Mikael LG, Rozen R (2008). Homocysteine modulates the effect of simvastatin on expression of ApoA-I and NF- $\varkappa \mathrm{B} / \mathrm{iNOS}$. Cardiovascular research, 80, 151-8.

Newton K, Strasser A (2000). Ionizing radiation and chemotherapeutic drugs induce apoptosis in lymphocytes in the absence of FAS or Fadd/Mort1 Signaling Implications for Cancer Therapy. J Experimental Med, 191, 195-200.

Ohe Y (2002). Treatment-related death from chemotherapy and thoracic radiotherapy for advanced cancer. Panminerva medica, 44, 205-12.

Park H, Schoenfeld J, Mailhot R, et al (2013). Statins and prostate cancer recurrence following radical prostatectomy or radiotherapy: a systematic review and meta-analysis.
Annals of oncology, 24, 1427-34.

Pedersen TR, Olsson AG, Fargeman O, et al (1998). Lipoprotein changes and reduction in the incidence of major coronary heart disease events in the Scandinavian Simvastatin Survival Study (4S). Circulation, 97, 1453-60.

Qiu G, Xie X, Wang Z, et al (2014). Suppressive effects of simvastatin on the human acute promyelocytic leukemia NB4 cell line through the regulation of the nuclear factor- $x \mathrm{~B}$ signaling pathway. Oncology Letters.

Rao AD, Milbrandt EB (2010). To JUPITER and beyond: statins, inflammation, and primary prevention. Critical Care, 14, 310 .

Relja B, Meder F, Wilhelm K, et al (2010). Simvastatin inhibits cell growth and induces apoptosis and G0/G1 cell cycle arrest in hepatic cancer cells. International Journal Of Molecular Medicine, 26, 735 .

Robinson AB (2013). Radiation hormesis, cancer, and freedom in American medicine. J Am Physicians and Surgeons, 18.

Saito A, Saito N, Mol W, et al (2008). Simvastatin inhibits growth via apoptosis and the induction of cell cycle arrest in human melanoma cells. Melanoma Res, 18, 85-94.

Sandhu S, Wiebe N, Fried LF, et al (2006). Statins for improving renal outcomes: a meta-analysis. J Am Society of Nephrol, 17.

Schachter M (2005). Chemical, pharmacokinetic and pharmacodynamic properties of statins: an update. Fundamental Clin Pharmacol, 19, 117-25.

Spampanato C, De Maria S, Sarnataro M, et al (2012). Simvastatin inhibits cancer cell growth by inducing apoptosis correlated to activation of Bax and down-regulation of BCL-2 gene expression. International J Oncol, 40, 935-41.

Tan M, Song X, Zhang G, et al (2013). Statins and the risk of lung cancer: a meta-analysis. PloS one, 8, e57349.

Thurnher M, Nussbaumer O, Gruenbacher G (2012). Novel aspects of mevalonate pathway inhibitors as antitumor agents. Clin Cancer Res, 18, 3524-31.

Tu Y-S, Kang X-L, Zhou J-G, et al (2011). Involvement of Chk1Cdc25A-cyclin A/CDk2 pathway in simvastatin induced S-phase cell cycle arrest and apoptosis in multiple myeloma cells. European J Pharmacol, 670, 356-64.

Vucic V, Isenovic E, Adzic M, et al (2006). Effects of gammaradiation on cell growth, cycle arrest, death, and superoxide dismutase expression by DU 145 human prostate cancer cells. Brazilian J Med Biological Res, 39, 227-36.

Wang Y, Xu S-L, Wu Y-Z, et al (2013). Simvastatin induces caspase-dependent apoptosis and activates P53 in OCM-1 cells. Experimental eye research, 113, 128-34.

Xie X, Tang Y (2007). Efficient synthesis of simvastatin by use of whole-cell biocatalysis. Applied and environmental microbiology, 73, 2054-60.

Zhang W, Wu J, Zhou L, et al (2010). Fluvastatin, a lipophilic statin, induces apoptosis in human hepatocellular carcinoma cells through mitochondria-operated pathway. Indian Journal of Experimental Biology.

Zhao R, Gish K, Murphy M, et al (2000). Analysis of p53regulated gene expression patterns using oligonucleotide arrays. Genes \& development, 14, 981-93.

Zhou Z-H, Zhou Z, Shi Q, et al (2005). Sensitization of multiple myeloma and B lymphoma lines to dexamethasone and $\gamma$-radiation-induced apoptosis by CD40 activation. Apoptosis, 10, 123-34. 